\title{
14
}

\section{Fictional Realism and Negative Existentials}

\author{
Tatjana von Solodkoff
}

We have all been prone to say, in our common-sense usage of exist, that Pegasus does not exist, meaning simply that there is no such entity at all.

Quine (1948, 3)

Fictional realism is the view that fictional objects, such as Hermione Granger and Sherlock Holmes's violin, are part of the 'furniture of our world'. ${ }^{1}$ Realists take their view to be charitable to our ordinary conception of fiction and fictional characters, but no matter how well realism can accommodate common sense, there is one kind of talk with which it struggles: negative existentials.

The difficulties the realist faces when it comes to explaining utterances such as 'Holmes does not exist' have been pointed out more than once by fictional antirealists, who reject the existence of fictional characters. And Anthony Everett (2007) has recently argued that fictional realists cannot meet the explanatory challenges posed by negative existentials. Everett's discussion of the extant realist treatments of negative existentials about fictional objects is comprehensive, and the challenges he raises are interesting and important. And in order to overcome them, the fictional realist has to do more explanatory work than she has done so far. In this chapter, I

\footnotetext{
Many thanks for helpful and inspiring discussions go to Tim Crane, Kit Fine, Manuel García-Carpintero, Dominic Gregory, Steve Makin, Genoveva Martí, Friederike Moltmann, Eric Olson, Peter van Inwagen, Richard Woodward and, in particular, Anthony Everett. Earlier versions of this chapter were presented at a workshop in Paris as part of the ENS project 'Semantical Structure and Ontological Structure' and at the Postgraduate Research Seminar at the Logos centre in Barcelona and thanks go to my audience on both occasions. An early version was written during a visit on Friederike Moltmann's ENS project in Paris and I'd like to take this opportunity to thank both Friederike and her project for their financial and intellectual support. I'd also like to thank the Royal Institute of Philosophy who supported me financially with a Jacobsen Fellowship during the early stages of this paper. My work on this chapter was supported by the DGI, Spanish Government, research project FFI2010-16049 and Consolider-Ingenio project CSD200900056.

${ }^{1}$ Defenders of fictional realism include Kripke (1973), van Inwagen (1977; 1983; 2003), Wolterstorff (1980), Schiffer (1996), Salmon (1998), Thomasson (1999; 2003), Braun (2005).
} 
shall take up the defence on behalf of the fictional realist, and argue, contra Everett, that negative existentials are not the Achilles heel of fictional realism.

\subsection{Setting the Stage}

A variety of views can be subsumed under the term 'fictional realism', but the most popular approach is to hold that fictional characters are abstract objects, which inhabit the actual world and which are created by authors. Call this view fictional creationism. To focus discussion, I shall assume that the fictional realist is a creationist. ${ }^{2}$

One of the most attractive features of fictional realism is that it so well fits common sense when it comes to the popular activity we call literary criticism. Consider the following piece of critical talk: 'Some fictional characters are better known than others.' Common sense commits itself to the truth of this sentence and the fictional realist can accommodate this by offering a straightforward interpretation of the claim. By contrast, anti-realists who reject fictional characters need to find a way to reconcile their view with common sense. When it comes to accommodating literary criticism, fictional realists have a far simpler story to tell than their rivals, and thereby seem to enjoy an advantage over fictional anti-realists. ${ }^{3}$

When realists point out how well their view fits with common sense, anti-realists like to insist that realism looks a lot less commonsensical when we move away from literary criticism and consider negative existentials, such as the following sentences:

(1) a. Hermione Granger doesn't exist.

b. There's no Hermione Granger.

(2) a. There are no hobbits.

b. Hobbits don't exist.

As you will have already noted, the sentences ( $1 \mathrm{a} / \mathrm{b})$ feature a singular term which purports to refer to a fictional object, and sentences $(2 \mathrm{a} / \mathrm{b})$ contain a general term purporting to refer to a fictional kind. In contrast to some critics, I think general

2 Fictional creationism has its most vocal defenders in van Inwagen (1977; 1983; 2003), Salmon (1998) and Thomasson $(1999 ; 2003)$. Having said that, van Inwagen actually claims to be sitting on the fence when it comes to the question of whether fictional characters are created by authors or are more like Platonic objects: see his (2003). But since his rhetoric is clearly more mocking when it comes to non-creationist views - he complains that they reduce authors to mere flower arrangers-I'll treat him as a creationist here. My proposal is designed with fictional creationism in mind and if it is plausible I take this to speak in favour of creationism over other realist approaches.

3 Though 'pure' critical sentences such as the one mentioned are clearly the cart horse of fictional realism, the realist can also offer more or less straightforward interpretations for 'internal' claims such as 'Hermione Granger is a very bright student', and 'mixed' claims such as 'Doyle's most famous fictional character is the most famous detective of all times'. The former can be taken as elliptical for claims concerning what is true according to some contextually relevant fiction, while the latter kind of talk can be interpreted as mixing claims about properties a fictional character has (in reality) with claims about features it holds (according to the fiction). Compare van Inwagen (1977). 
negative existentials allow for a straightforward and unproblematic interpretation, but I shall delay discussion of this until later on in the chapter. For now, I shall focus on singular negative existentials. ${ }^{4}$ It is here where the realist faces the explanatory challenge of showing how she can reconcile her realism about fictional characters with the apparent truth of negative existentials.

One may wonder whether the realist really needs to go through the hassle of trying to accommodate negative existentials. The answer is that fictional realists not only take pride in their ability to accommodate common sense but also attempt to justify their view on the basis of this ability. If the realist were to simply dismiss negative existentials as being false then she would, at the very least, seem to place herself in the dialectically awkward position of attempting to dismiss part of the very phenomenon to which she is trying to appeal to justify her account. It's no wonder, then, that realists and anti-realists alike have thought that negative existentials are hugely important dialectically. Thus Kendall Walton $(2003,241)$ warns that if sentences like 'The Big Bad Wolf doesn't exist' are literally true, then 'it is hard to avoid concluding that those fictitious things are nothing at all, that they simply are not, period'. And Amie Thomasson, one of the most vocal defenders of fictional realism, has acknowledged that handling negative existentials is the 'central problem' facing the realist $(2003,214)$.

Of course, fictional realists haven't simply ignored the fact that we utter negative existentials. It is beyond the scope of this chapter to assess all of the extant proposals that have been offered in the literature, but the goal of the next section is to introduce two prominent strategies, with a view to developing a novel solution to the problem of negative existentials in the later sections of this chapter. In particular, I will argue that a proposal originally offered by Thomasson (1999) can be developed in such a way as to deliver the results the fictional realist was after.

\subsection{Negative Existentials within a Realist View}

How can the realist acknowledge the truth of (1) given that her ontology certainly contains Hermione? Initially, it might appear attractive to interpret (1) as saying that Hermione is a fictional character. ${ }^{5}$ But this proposal has the considerable cost of rendering negative existentials trivial in contexts where they don't seem to be. For consider the conjunction 'Hermione does not exist, she's just a fictional character'. On the present proposal, this sentence would be understood as saying that Hermione is a fictional character and that she is a fictional character-which means that neither conjunct adds any information to the other. But surely that is not how we feel about the sentence, the second conjunct adds a piece of information to the first we did not possess before.

4 I shall drop 'singular' in the following, it should be clear from context when I talk about non-singular negative existentials.

5 This was suggested by van Inwagen in personal communication. 
An alternative proposal, suggested by Peter van Inwagen $(1977,308)$, looks more promising:

[The speaker of 'Mr Pickwick does not exist'] would probably be expressing the proposition that there is no such man as Pickwick, or, more precisely, the proposition that nothing has all the properties ascribed to Pickwick.

On this proposal, an utterance of 'Hermione doesn't exist' is interpretable as expressing the proposition that there is no thing that has all the properties that Hermione has according to the fiction. Though we can imagine how this proposal can handle most or all of the standard cases, troubles begin when we suppose that a speaker is suddenly confronted with a woman who has all and only the properties that Hermione has according to the novel-a situation that is imaginable for all intents and purposes. If van Inwagen's proposal were adequate, we would be within our rights to expect our speaker to withdraw his previous claim immediately. But that would be a mistake. Even if there were someone who has all these properties, that person would not be Hermione Granger, the fictional character created by J. K. Rowling. ${ }^{6}$

Moreover, van Inwagen's proposal is also incompatible with what sounds like a perfectly consistent sentence: 'Though Doyle's Holmes doesn't exist, I happen to know someone called "Holmes", who is exactly the way Holmes is described in Doyle's books.' If the current proposal were adequate, I would contradict myself when uttering this sentence, claiming initially that there is no one who has all the properties ascribed to Holmes in the fiction, and then following that up by claiming that I know some such person. But while my utterance expresses a falsehood, this is not due to its being contradictory. We need a proposal that has something to say about such unlikely, but perfectly coherent, cases.

Though van Inwagen's proposal has a degree of intuitive support-there is some plausibility to the thought that the speaker who asserts that Hermione doesn't exist is claiming that there is no woman who studies to become a female wizard and has all of the other properties fictionally ascribed to Hermione-the possible doppelgänger ruins the show and forces us to search for another remedy. And things look promising for the fictional realist when we consider the following suggestion by Amie Thomasson $(1999 ; 112):^{7}$

Statements like 'there is no Lear' [are] quite naturally interpretable as [claiming] that ... 'there is no (real) person who is Lear'.

6 Compare Kripke (1973), who tells us that if we came across creatures which had most of the properties ascribed to hobbits or unicorns, those things still wouldn't be hobbits or unicorns. To be sure, things might well be different if Rowling had led us to believe that Hermione was her creation when she was really writing about the person the speaker is confronted with. But that's not the kind of case we're considering.

7 Thomasson is here leaning on an earlier proposal made by Parsons (1980). Salmon's (1998) approach to such claims has similarities to Thomasson's. But in order to focus discussion I'll only talk about Thomasson's proposal here. 
Thomasson does not face the embarrassment that van Inwagen faces when presented with a Lear-doppelgänger. For not even the Lear-doppelgänger is identical to the fictional character Lear. ${ }^{8}$ At the same time, Thomasson's proposal has an initial ring of plausibility to it. It seems to be one of these interpretations where the folk would be happy to respond by saying 'Yes, that's exactly what I meant'.

Thomasson (1999) only tackles a quite limited range of negative existentials, and it's noticeable that she is mainly concerned with quantificational 'there is' constructions as opposed to predicative 'exists' constructions. But in an attempt to give Thomasson's approach a broader application, Anthony Everett (2007; 65) suggests a proposal along the following lines (in what follows I shall refer to it as Thomasson's proposal, but bear in mind that it's really Everett's interpretation of Thomasson):

A speaker may use an utterance of the form ' $a$ does not exist' to convey the claim that $a$ is not a K, where (i) $\mathrm{K}$ is a conversationally salient kind and (ii) $a$ is fictionally characterized as being a $\mathrm{K}$ in a conversationally salient fiction.

This proposal relies on the fact that fictional objects are usually fictionally described as belonging to some kind: as being women or detectives or animals or horses, and so on. (Note that 'kind' here is not limited to natural kinds, indeed, the notion should be understood in a much wider sense, where e.g. blue candles, might well form a kind too.) The subsequent thought is that we can appeal to these kinds to fix the value of $\mathrm{K}$ in a particular context. And Thomasson's proposal does indeed appear to make the right predictions with respect to paradigmatic negative existentials like 'Hermione doesn't exist' and 'Holmes doesn't exist'; in both cases, there is a salient kind that the character belongs to in their 'home' fiction and to which we can fix the value of $\mathrm{K}$ in order to deliver the result that speakers who utter such claims speak truly.

Things, however, don't go as smoothly when we encounter some less paradigmatic cases. Everett asks us to consider cases in which the fiction remains silent about the kind to which the fictional object belongs. Suppose an author wrote a rather unusual story about Yugo (and let us suppose that there he's not writing about a real thing). For all you as a reader know, Yugo could be a person or an animal or even a mineral! The fiction simply remains silent on these matters. But despite the fact that Yugo is not fictionally described as belonging to any particular kind, the following is certainly true:

Yugo doesn't exist.

The problem for Thomasson is that, though we have no trouble recognizing this claim as being true, we struggle to come up with a conversationally salient kind $\mathrm{K}$ in terms of which we can interpret the negative existential. But then what explains the truth of the negative existential? It seems that cases such as these fall into an explanatory gap if we adopt Thomasson's proposal, and it's not hard to see why. For

8 Of course, talk of a doppelgänger is strictly speaking inappropriate; if there were a real man Lear he would not be anything like Lear. For one thing, the fictional Lear is abstract while the man would be concrete. Grant me poetic licence. 
Thomasson's approach makes it mandatory that the fictional object in question is described as belonging to some particular kind in the fiction; and the Yugo-fiction doesn't meet this demand. Clause (ii), then, is the source of the trouble. ${ }^{9}$

Once we keep in mind the restrictions that clause (ii) places on the kinds that are candidate semantic values for $\mathrm{K}$, it's not too difficult to construct additional examples that are problematic for Thomasson's proposal. Consider e.g. Braingirl, the fictional character invented by the protagonist of Salman Rushdie's Fury. While Braingirl is a fictional character in Fury, she's also a fictional character 'in reality'. And, again, it seems as though we'd speak truly if we were to say:

Braingirl doesn't exist.

Thomasson's proposal, however, seems unable to accommodate the truth of this sentence. For given that fictional character is the most salient kind Braingirl is fictionally described as belonging to in the fiction, the defender of Thomasson's approach is forced to say that a speaker who claimed that Braingirl doesn't exist would be interpretable as saying that no real fictional character is identical to Braingirl. But given that the fictional realist accepts that Braingirl is a real fictional character-and it is prima facie difficult to see how she can deny that-then Thomasson's proposal commits the realist to holding that 'Braingirl doesn't exist' is false. And, as should be clear, that's hardly the result the realist was after. ${ }^{10}$

In both the Yugo case and the Braingirl case, the troubles are generated due to the demand that the semantic value of $\mathrm{K}$ is a kind that the target fictional character belongs to in the relevant story. And so a natural response would be to simply drop clause (ii) from the proposal. It's important to note that this doesn't itself change anything about the semantic claim that is integral to Thomasson's proposal. For that is just the following:

' $a$ does not exist' is true in context c iff $a$ isn't a KC

But as Everett (2007) interprets her, Thomasson's proposal involves more than a simple semantic recipe that we can follow in order to specify the truth-conditions for negative existentials: it also involves a substantial claim about the range of kinds from which the value of $\mathrm{K}_{\mathrm{C}}$ is fixed (in a context). That is, the only candidate semantic values are those kinds to which the target character belongs in their fiction. And whilst Thomasson's own examples were suggestive of a constraint like this, it's far

9 The idea that Yugo is not described in the fiction as belonging to any kind may invite the response that Yugo is surely described as belonging to some kinds in a weak sense; e.g. Yugo is described as a thing which meets some condition. But suppose that Yugo only holds the property of being self-identical. Clearly that won't help the proponent of Thomasson's proposal, since the fictional character Yugo really does meet this and other conditions. On a more autobiographical note, I have troubles trying to imagine a fiction that doesn't give us any suitable clue as to what kind of thing Yugo is. Isn't it noticeable that Everett doesn't tell us the story but simply states that such a story may exist? Hence, the fictional realist might just as well challenge him to come up with a plausible actual fiction first.

10 Perhaps some realists would want to resist by claiming that fictionally fictional characters aren't real fictional characters. I find this move implausible, and it is worth noting that it won't help in all the cases since similar problems will arise with real fictional characters that only hold properties that they really have. 
from clear that the fictional realist needs to wed herself to anything so strong. What's true is that the fictional realist can't simply try to explain away negative existentials by appealing merely to this semantic proposal: she clearly needs to say something about what the semantic values of $\mathrm{K}_{\mathrm{C}}$ actually are in a variety of contexts, and we'd expect a relatively systematic story at this point. But the problems that we have outlined only show that one attempt to enrich the semantic proposal fails to generate the right results in a number of cases. And as should be clear, that leaves it very much open whether the semantics can be enriched in some other way to give more palatable results.

\subsection{Towards a New Proposal}

Suppose that the fictional realist frees Thomasson's proposal from the chains of clause (ii), and no longer holds that the candidate values for $\mathrm{K}$ are restricted to those that Yugo belongs to in the associated fiction. What the realist needs to show is that there's a kind which can plausibly be the value of K in a context in which 'Yugo doesn't exist' might be uttered.

At first glance, fixing the value of $\mathrm{K}$ to the kind real man seems to get the right result: whatever he is, Yugo is certainly not a real man. However, the realist should not be blinded by the ready availability of this assignment. For one thing, if the realist holds that $\mathrm{K}$ is assigned the value real man (in a context) it seems like she's plucked a semantic value out of thin air for no other reason than that doing so allows her to maintain that 'Yugo doesn't exist' expresses a truth (in that context). For another thing, interpreting 'Yugo doesn't exist' as expressing the proposition that Yugo is not a real man yields too weak an interpretation. When an ordinary speaker claims that Yugo doesn't exist, it's natural to think that they are not only ruling out that Yugo is a real man. They seem to be saying something stronger: that Yugo is neither a real man, nor a real human, nor a real animal, nor a real mineral, etc. And that's because he-or rather it—is not a real thing!

The previous point also has direct consequences for Thomasson's original idea that a speaker who says that Holmes doesn't exist is claiming that no real man is identical to Holmes. Even though this interpretation is charitable, it also seems too weak. And to see that just note that, if Thomasson were right, a speaker who said that Holmes doesn't exist would be allowed to immediately follow that denial with the flat out assertion that Holmes isn't a real court jester. That is, it would be felicitous to utter 'Holmes doesn't exist, and he isn't a real court jester'. But, once again, this seems offlimits and not for the trivial reason that Holmes isn't a real court jester: Holmes's being a real court jester (or alien, or mineral, or cherry stone) is itself ruled out by the speaker when they deny the existence of Holmes. What the speaker seems to be ruling out, once again, is that Holmes is a real thing.

'But hold on', Everett may reply, 'saying that Yugo is not a real thing isn't a viable option for the fictional realist'. For, 
in so far as the [fictional realist] seems committed to holding that fictional abstract objects such as [Yugo] exist, she is presumably also committed to holding that fictional objects are real things. For one thing, it seems decidedly odd to claim that fictional objects exist and are abstract objects but not real things ... the abstract object theorist herself needs to allow that fictional abstract objects such as [Yugo] are real things. $(2007,70)$

What might actually strike us as the most natural understanding of negative existentials such as 'Hermione doesn't exist'-Hermione is not a real thing-has to be strongly opposed to by the fictional realist, if the folk's usage of 'not real' is taken to mean 'not existent' or 'not in one's ontology'.

But as Jonathan Schaffer $(2009,360)$ notes, the adjective 'real' is 'used flexibly in ordinary English to mark a multitude of distinctions'. As the vagaries of natural language go, 'real' is a rather slippery term with more than one or two uses, and the most relevant for our purposes include: existent; occurring in the physical world; not imaginary, fictitious, pretended or theoretical; actual. And even if Everett is right to point out that the realist accepts that there is one reading of 'real thing' on which Holmes is a real thing, it's open to the realist to deny that this is the same sense of reality that is relevant when an everyday speaker denies the reality of Hermione and her ilk. But even if the realist denies this, she has plenty of plausible options left.

For instance, the realist may interpret an ordinary speaker who claims that Hermione isn't real as saying that Hermione isn't a concrete object. ${ }^{11}$ After all, we normally think of real things as being the kind of things you can meet, bump into, and interact with in the physical world. And since the fictional realist was already committed to holding that Hermione isn't a concrete object, she can maintain that there is a sense in which Hermione isn't a real object without thereby compromising her realism. Indeed, there is a prima facie case in favour of fixing the value of $\mathrm{K}$ to concrete object whenever possible. It is, after all, plausible to suspect that the folk usually picture a concrete object when confronted with a name. You hear me say 'Let me reveal to you the truth about Esther', and you probably prepare yourself for insights about a person. 'I heard a rumour concerning Glueburg' might trigger pictures of people as well as cities or locations in you. You are encouraged to imagine something, to picture a concrete object. (The same, in fact, applies to Yugo. When Everett announces 'I'll tell you a story about Yugo', then I will acknowledge his efforts by picturing a man or maybe a cat or possibly even a semi-precious gemstone-in any case I'll picture a concrete thing.) But even though concrete object may well be the first choice whenever it is among the available values, it is oftentimes not the only value that can be assigned to $\mathrm{K}$ in order to predict the right results. ${ }^{12}$

\footnotetext{
11 Compare Sainsbury $(2009,109)$ who writes: 'Maybe it would be best for the [creationist] to explore treating "exists" as ambiguous, or context-sensitive: sometimes when we use the word we mean to include everything, concrete and abstract, sometimes we mean to include only the concrete.'

12 There is an obvious worry about the suggestion that 'Hermione doesn't exist' should be interpreted as 'Hermione is not a concrete object': the suggestion threatens to overgenerate badly and entail the truth of negative existentials about numbers and other abstracta. I think this shows that the realist cannot always
} 
The realist may also interpret an ordinary speaker who claims that Hermione isn't real as saying that Hermione is a pretend object. In doing so, the fictional realist does not compromise her realism. For even if the fictional realist accepts that fictional objects are pretend objects, she may insist that the relevant notion of a pretend object is consistent with the hypothesis that such objects exist. That is, the adjective 'pretend' can be taken to narrow down the class of objects being talked about. (Note that the adjective 'pretend' works as a modifier when it's preceding 'object': a pretend object (in the present sense) is still an object. Though, of course, a pretend detective isn't a detective anymore than a fake barn is a barn.) After all, recall that we're assuming that the fictional realist is also a creationist and will thereby accept that pretence plays an important role in the creation of a fictional character. The core idea associated with pretence here is that authors, when writing a fiction and using fictional names, pretend to refer to a woman or a detective or a hobbit, depending on what the object in question belongs to according to the fiction. And again, even if there is a sense in which the realist holds that Holmes isn't a pretend object - there are uses of 'pretend' whereby it works like 'fake' and in this sense the fictional realist will deny that Holmes is a pretend object-that's not to say that there isn't a sense in which she may hold that he is. Holmes is a pretend object insofar as he exists because an author used the name 'Holmes' in a pretenceful way when creating a fiction. In contrast, Obama is a serious object insofar as his existence has nothing to do with the pretenceful uses of his name. These might be more technical notions of 'pretend' and 'serious' than ordinary speakers have in mind when they say that things are 'only pretend' or 'not serious' but they are notions that make sense within the context of fictional realism nonetheless.

Next, notice that if she interprets a speaker who denies the existence of Yugo as denying their reality, the fictional realist can handle the Yugo case easily if she understands 'real' as picking out the concrete objects or as picking out the serious (i.e. non-pretend) objects. For the proposal tells us that the relevant value for $\mathrm{K}$ in such a context is either the kind serious object or the kind concrete object and so a token utterance of 'Yugo doesn't exist' would, depending on context, either express the true proposition that Yugo is not a serious object or the equally true proposition that Yugo is not a concrete object. In exactly the same way, a speaker who denies the existence of Braingirl can either be interpreted as claiming that Braingirl isn't a serious object or as claiming that Braingirl isn't a concrete entity. In other cases, where a fictional object is abstract in the fiction, we might prefer to assign serious object rather than concrete to K. Imagine, for instance, a fiction featuring the largest prime number, and let's say that its name in the fiction is 'Isnuq'. If there were a largest prime number, it would be abstract, so we might feel most comfortable to interpret 'Isnuk doesn't exist' as claiming that there's no serious object identical to Isnuk. But note that fixing $\mathrm{K}$ to concrete object would deliver the right result just as well. 
To be clear: the proposal is not quite that ordinary speakers who deny the existence of Hermione are expressing the proposition that Hermione is not a real thing. Rather, the idea is that ordinary speakers will naturally regard 'Hermione doesn't exist' and 'Hermione isn't real' as being interchangeable in everyday contexts. And even if Everett is right to point out that there is a sense in which the fictional realist holds that Hermione does exist and is real, the crucial point is then that there are a variety of ways to understand the notion of a real object, and on some of these the fictional realist can happily agree that Hermione isn't real. The upshot is that the bare bones of Thomasson's semantic proposal are retained: ' $n$ doesn't exist' is true in a context c iff $n$ isn't a $\mathrm{K}_{\mathrm{C}}$. What has changed is that the original proposal about the interpretation of $\mathrm{K}$, which tied the candidates to the kinds that Hermione fictionally belongs to, has been replaced by a proposal according to which everyday existence denials are interpreted by means of the kinds serious object and concrete object. And as we've seen, this proposal delivers acceptable results in cases where Thomasson's proposal breaks down. Moreover, the proposal also makes sense of why speakers who deny the existence of Hermione are ruling out more than her mere humanity, for it provides the realist with a way to make sense of the idea that Hermione isn't a real anything.

Though Everett disparages the thought that the fictional realist can legitimately interpret negative existentials as claiming that the target characters are not real things, I contend that the realist can make sense of the idea that Hermione and her ilk are not real in a perfectly ordinary sense of that term. Indeed, a very natural option for the realist is to hold that, when speakers deny the existence of a fictional character, they are claiming that the target character is not a $\mathrm{K}$, where the candidate values for $\mathrm{K}$ include at least two- - those of serious object and concrete object - that offer charitable and plausible interpretations by the lights of the fictional realist, and, moreover, interpretations which do not fall apart when faced with cases such as Yugo and Braingirl.

\subsubsection{More Cases to Manage}

So far, we have only looked at simple cases in which speakers deny the existence of a single fictional character. But the linguistic data are clearly not limited to such cases, and the present proposal needs to be shown to be adequate not only to the basic examples but to more complex ones too. Take the following claim:

Neither Holmes nor his violin exist.

Everett suggests that this case is troubling for Thomasson because she must scramble around trying to find some kind to which both Holmes and his violin belong in the fiction, since the sentence appears to deny existence of Holmes and his violin in exactly the same way. On the new proposal, things look far more straightforward: the relevant value of $\mathrm{K}$ in this case may either be the kind serious object or the kind concrete object, and since Holmes and his violin are abstract pretend objects, the proposal verifies the sentence correctly. 
The new proposal can also handle more complex sentences. Take an example that Everett considers particular tricky for the realist:

Obama exists but Raskolnikov and the round square don't.

Everett argues that this sentence denies existence of Raskolnikov in exactly the same way as it denies of the round square. But because the fictional realist usually feels only committed to fictional characters, rather than also to other figments of imagination, it seems that she needs to interpret the sentence as denying existence of the round square in the ordinary sense which excludes the object from the stock of reality. As Everett puts it, the sentence 'must deny the existence of the round square in the ordinary sense, in the sense that excludes the round square from our ontology' (2007, 62 ). But then we seem forced to interpret the speaker as excluding both the round square and Raskolnikov from the ontological realm-an interpretation that isn't to the realist's taste.

On our current proposal the truth of the sentence can be explained without putting the realist in a compromising situation. For the truth-condition it associates with the sentence can be specified as the following:

'Obama exists but Raskolnikov and the round square do not' is true in context $\mathrm{c}$ iff Obama is a $K_{C}$ but it is not the case that Raskolnikov is a $K_{C}$ and it is not the case that the round square is a $K_{C}$ either.

Let's work through the conjuncts in turn. Clearly Obama is a concrete, serious object. So the first conjunct of the truth-condition is true on either reading. And for the realist at least, Raskolnikov is an abstract, pretend object. So the second conjunct is true on either reading too. But what of the third conjunct?

Well, unless she wants to accept an ontology that includes impossible objects, the fictional realist will hold that the expression 'the round square' is an empty term. But then it seems plausible that the realist can make the case that it is indeed false that the round square is a $K_{C}$ whatever context we're in. She might e.g. give 'the round square' a Russellian treatment and explain that there is no unique round square and, hence, that it is false that the round square is a $\mathrm{K}_{\mathrm{C}}$. Or maybe the realist will feel empty terms are best accommodated by embracing a negative free logic, and so hold that any atomic sentence involving an empty term has a true negation, meaning that it is indeed not the case that the round square is a $\mathrm{K}_{\mathrm{C}}$. Either way, the realist can make the case that the truth-condition associated with 'Obama exists but Raskolnikov and the round square do not' obtains. Everett may be right that the realist's explanation of why the truth-condition associated with 'The round square doesn't exist' obtains is different from her explanation of why the truth-condition associated with 'Raskolnikov doesn't exist' obtains. But that's not to say that the realist thinks that the two sentences have different truth-conditions. The two sentences deny existential status in the same sense-there are no serious/concrete objects that are Raskolnikov or the unique round square - but the reason why their respective truth-conditions obtain is different. 
What about failed posits of science? What can the fictional realist say about the truth-condition of the following sentence?

Obama exists but Hermione and Vulcan don't.

Again, the issue turns on how the realist wants to treat terms allegedly referring to the posits of false scientific theories. If she thinks these terms are just as empty as the definite description 'the round square' then her options mirror those just discussed. But it's not uncommon for fictional realists to accept into their ontology not only fictional entities but the posits of failed science too. Thus Nathan Salmon (2002) argues that both Hermione and Vulcan belong to a broader category of things he calls mythical objects. But notice that the realist who follows Salmon, and embraces the existence of Vulcan, can accommodate the sentence if it is understood as saying that, whilst Obama is concrete, Hermione and Vulcan are not. Moreover, even if she denies that Vulcan is a pretend object, the realist could expand the category of nonserious objects to include any mythical object. And then she can interpret the above sentence as saying that whilst Obama is a serious object, Hermione and Vulcan are not. $^{13}$

What about the following troubling case?

The fictional character Hermione Granger doesn't exist.

Well, I can't speak for everyone, but my intuitions about this sentence are far from clear. At the very least, there seems to be one reading under which this sentence is false: it's the reading we get when we transform the sentence into a 'there is' construction to arrive at 'There is no fictional character Hermione Granger'. It seems to me more than clear that this sentence is false when interpreted straightforwardly: if I told someone that there is no fictional character Hermione Granger, I'd expect to be told to go to my local bookshop and buy the Potter-stories.

In light of this, I'm tempted to conclude that 'The fictional character Hermione Granger doesn't exist' has a false reading. But what is it? The relevant value of $\mathrm{K}$ in its truth-condition cannot be fixed to either serious object or concrete object, since either interpretation would entail that the sentence expresses a truth. However, if we fix the variable to fictional character we obtain the desired result. The realist who adopts the present proposal can interpret 'The fictional character Hermione Granger doesn't exist' as saying that no fictional character is identical to Hermione Granger-a claim that is false. Of course, that's not to say that the sentence lacks a natural reading on which it turns out to be true-even though it might not be the most natural reading in all cases-under which it can be interpreted analogously to the sentences we looked at previously, namely as 'The fictional character Hermione Granger is not a real thing. As in the previous cases, the kinds concrete object and serious object may

13 Note that this kind of fictional realist can even explain the truth of 'Obama and the number three exist, but Hermione, Vulcan, and the round square don't'. And the point is that Hermione, Vulcan, and the round square- unlike Obama and the number three-fail to be serious objects. As before, that's compatible with holding that Hermione, Vulcan, and the round square fail to be serious objects for different reasons. 
be assigned, resulting in the interpretation of the sentence that no concrete/serious object is identical to the fictional character Hermione Granger, which is obviously true.

\subsubsection{Superheroes and Kryptonite}

Takashi Yagisawa $(2001,169)$ objects to Thomasson's proposal on the grounds of two observations that puzzle him. The first worry concerns how Thomasson's proposal generalizes to cover negative existentials that don't feature singular terms but instead feature terms like 'hobbits'. He writes:

[Thomasson's proposal] has counterexamples: e.g., '[Superheroes] do not exist.' When we deny the existence of [Superheroes] on the grounds that they are fictional, we need not be able to give a sortal or other kind term to fill the gap in 'There are no such ( ) as [Superheroes]' except for such an empty kind term as 'things' or 'entities'. Since [fictional realists] maintain that [Superheroes] exist ... it is false to say that there are no such things, or entities, as [Superheroes].

But Yagisawa doesn't think the troubles end here. He continues:

Another difficulty with [the proposal] is that it is unable to account for the apparent truth of some general statements: e.g., 'All fictional individuals are unreal,' 'All fictional individuals are non-existent,' 'No fictional individual exists,' ... The paraphrasing strategy of [Thomasson' proposal] does not apply here.

Let's see how the new proposal handles these alleged problem cases in sequence.

Now, Yagisawa seems to misunderstand the realist's position, since he takes the realist to accept that there are things that instantiate the property of being a superhero. We can see where this thought comes from. Fictional characters exist. Superheroes are fictional characters. So there are such things as superheroes. But realists would not accept that reasoning. Rather, they commit themselves to the idea that there are objects, fictional objects, which hold the property of being a superhero, or that are such that according to their associated fiction are described as being superheroes. ${ }^{14}$ Contra Yagisawa, they do not maintain that superheroes or hobbits or magic rings exist.

One natural thought, then, of how to handle such general negative existentials is to interpret them as follows, call it the 'naïve proposal':

'Fs don't exist' is true iff there is no $x$, such that $x$ is an $F$.

The naïve proposal delivers the right results in the sense that it correctly verifies that e.g. 'Superheroes don't exist' and 'Neither hobbits nor magic rings exist' express truths. But it has the disadvantage of not fitting into the new proposal all too well. For the view I defended earlier held that negative existentials are interpreted by means of

14 The former is how van Inwagen would reply to Yagisawa's objections, the second one might be appreciated by Thomasson. 
kinds. In order to obtain a uniform semantical theory this had better apply to singular and general negative existentials alike.

There's no need to worry, however, for the realist may interpret general negative existentials in the spirit of the new proposal. When the folk deny the existence of superheroes, we can interpret them as saying that superheroes don't belong to the contextually specified kind; a kind which is among the range of the ones available for interpretation, such as concrete object or serious object. This endows the realist with the following truth-condition:

'Fs don't exist' is true in $\mathrm{c}$ iff there is no $x$, such that $x$ is a $\mathrm{K}_{\mathrm{C}}$ and $x$ is an $F$.

Applied to our superheroes, an utterance of 'Superheroes don't exist' would be true in this context iff nothing is both a $\mathrm{K}_{\mathrm{C}}$ and a superhero. This proposal fits neatly with the previous suggestion of how to interpret singular negative existentials. Moreover, and like the naïve proposal, it verifies what we expect it to verify. What comes in handy is that here we don't even need to worry about what the value of $\mathrm{K}$ gets fixed to in a given context. For the falsity of the second embedded conjunct-remember that nothing has the property of being a superhero, even on the realist's view-ensures that the truth-condition obtains and, hence, that the target claim expresses a truth.

That the present treatment of general negative existentials fits well with my earlier account of their singular relatives is an attractive feature of the proposal. But that's not all, for the proposal also allows us to deal with Yagisawa's second objection and accommodate one case with which the naïve proposal struggles.

The thought behind Yagisawa's second objection is that some apparently true sentences predicate properties of fictional characters which the fictional realist thinks that they don't really have. So, for instance, in addition to denying the existence of Hermione et al., we appear to predicate unreality or non-existence of fictional characters. And such claims look to be true by ordinary standards, but unacceptable by the lights of the fictional realist. Now, I take 'Fictional characters are unreal', 'Fictional characters are non-existent', 'Fictional characters are not real' and 'Fictional characters don't exist' to be four different ways to convey the same claim. As I noted earlier, this seems to be plausible, since ordinary speakers find it extremely natural to switch between claiming that something 'is not real' and claiming that that thing 'doesn't exist'.

In light of this, let's focus on the following example, since it appears to be paradigmatic of the problem that Yagisawa takes himself to have identified: ${ }^{15}$

Fictional characters don't exist.

Even though the defender of the naïve proposal does not think that anything has the property of being a superhero, she does of course believe that things have the property of being fictional characters. But that means the present case is one that the naïve proposal cannot handle, for the realist simply cannot hold that 'Fictional

15 Everett, too, presents this sentence as being particularly tricky for the fictional realist. See Everett (2007, 68-70). 
characters don't exist' is true iff there is no $x$, such that $x$ is a fictional character. After all, the core of the realist's view is precisely that there are fictional characters.

On the new proposal things are a lot rosier, however. For the proposal assigns the following truth-condition:

'Fictional characters don't exist' is true in $\mathrm{c}$ iff there is no $x$ such that $x$ is a $\mathrm{K}_{\mathrm{C}}$ and $x$ is a fictional character.

In the earlier cases of general negative existentials, the fictional realist had an automatic guarantee that the truth-condition for (e.g.) 'Hobbits don't exist' obtained because nothing, on her view, has the property of being a hobbit. Not so in the present case: according to the realist, some things do have the property of being a fictional character. But the truth-condition obtains nonetheless, because the first embedded conjunct fails to be true. Thus if the value of $\mathrm{K}$ is fixed to the kind serious object, then a speaker who uttered 'Fictional characters don't exist' would express the true proposition that nothing is both a non-pretend object and a fictional character-which gives us the right result since it verifies the original sentence. ${ }^{16}$

The final range of problem cases I shall consider are those negative existentials involving mass nouns as in 'Neither Kryptonite nor Atlantis exist.' Everett considers this sentence tricky for the realist, since the sentence

seems to deny existence to both [Kryptonite] and Atlantis in exactly the same sense. So our account of the existence predicate must allow that it functions in exactly the same way when it combines with singular terms and when it combines with mass terms. $(2007,67)$.

Now, we know what to say about the second element taken for itself. 'Atlantis doesn't exist', as uttered in c, is true when and only when there's no $x$ such that $x$ is a $\mathrm{K}_{C}$ and $x$ is identical to Atlantis. But Kryptonite can't be simply treated as a singular term denoting an individual, for it's not a countable thing. As a result, there is no thing such that $i t$ is identical to Kryptonite.

But it's far too quick to conclude from this observation that we have found a spectre for the realist's treatment of negative existentials.

For one thing, the problem seems to be about mass terms in general. After all, the problem that Everett raises also arises in simple cases which have nothing to do with fiction, such as 'Both water and the moon exist.' So it's natural to look first at how mass terms are treated semantically and then develop a treatment of Everett's example on that basis. And one mainstream view in the literature on how we understand mass nouns semantically thinks of mass nouns as referring to

\footnotetext{
16 I am here only talking about mere fictional characters, which excludes Napoleon and Queen Victoria. If we were to include them, the sentence would be intuitively false, which is also what the proposal predicts.
} 
portions or quantities of stuff when they are used in conjunction with quantificational expressions. ${ }^{17}$ Thus, the mass noun 'water', as in 'All water is transparent', is taken to denote portions/quantities of water, and the sentence is true just in case all portions/quantities of water are transparent. And if that's right, then we can say the same about 'Kryptonite', the fictional mass noun denotes portions of Kryptonite. The realist may then suggest the following truth-condition for the original sentence:

'Neither Kryptonite nor Atlantis exist' is true in c iff no portion of Kryptonite is a $\mathrm{K}_{\mathrm{C}}$ and Atlantis isn't a $\mathrm{K}_{\mathrm{C}}$ either.

Note that just as the realist holds that nothing has the property of being a hobbit, she will also hold that nothing has the property of being a portion of Kryptonite, and so no quantity of Kryptonite will be a $\mathrm{K}_{\mathrm{C}}$ whatever the relevant kind is in context. But that doesn't mean that the complex sentence is verified, since there is a fictional entity referred to by 'Atlantis', and so the value of $\mathrm{K}$ does matter in this particular case. But as before, the realist does not have to look very far for a plausible interpretation: concrete object and serious object are both readily available. Hence, if the realist adopts the new proposal she can happily accept that 'Neither Kryptonite nor Atlantis exist' can be used to express a truth. ${ }^{18}$

\subsection{Walton's Objection}

As Everett interprets her, Thomasson's original proposal has it that the truthconditions of sentences that deny the existence of fictional characters can be rendered as negated existential quantifications such as ' $\neg \exists x$ ( $x=$ Hermione)'. And when we take such claims to be true, the idea is that the relevant domain of quantification is implicitly restricted to less than all that there really is. ${ }^{19}$

Kendall Walton (2003) has suggested that this proposal is inadequate because it cannot explain important differences between the ways in which we use quantificational expressions on the one hand and the existence predicate on the other. $\mathrm{He}$ writes:

Although domain restrictions on quantified 'there is no' and 'there are no' constructions are perfectly common and ordinary, predicative statements concerning

17 'Portion' is Montague's (1979) preferred term, Zimmerman (1995) thinks 'mass' is more adequate, Burge (1972) and Chappell (1970) choose 'quantities' and 'parcels' respectively. See the first part of Zimmerman (1995) for a broader discussion of the literature on this topic.

18 An anonymous reader for this volume asked whether I am saying that the realist should accept there are fictional portions in addition to fictional objects. The answer is that I think that the realist should accept there are fictional portions only in the same sense that they accept that there are fictional detectives. The realist thinks that there are fictional detectives only insofar as there are fictional objects that are, according to certain fictions, detectives. Similarly, the realist should accept that there are fictional portions of Kryptonite only insofar as there are fictional objects that are, according to certain fictions, portions of Kryptonite.

19 See Everett $(2007,67)$. The objection from Walton that will concern us seems to interpret Thomasson in this way too. 
existence do not admit of correspondingly restricted readings ... Suppose 'Charlie' is the name of a particular Cheetah. 'Charlie doesn't exist' is hardly a comfortable way of saying just that Charlie is absent from the Taronga Zoo, that he is somewhere else, if anywhere ... This suggests that the use of 'exists' prevents the quantification from having a contextually determined domain restriction. (2003, 240-1)

So given that the existence predicate cannot be restricted to a particular domain in the way that quantificational expressions can, Thomasson's proposal cannot be right.

This objection needs to be handled carefully. As Friederike Moltmann has recently emphasized, the existence predicate does tolerate explicit restrictions. She offers the following examples:

- Giraffes exist (only in Africa),

- Wild ponies do not exist (in Germany),

- Pure air doesn't exist (in China) anymore, and

- Socrates doesn't exist (anymore).

But whilst these cases cast doubt on Walton's claim that the use of 'exists' itself prevents the quantification from having a contextually determined domain restriction, that doesn't itself remove the force of the worry. For even if the existence predicate does tolerate some restrictions, it doesn't seem to tolerate the same kind or variety of restrictions that are familiar from paradigmatic cases of quantifier domain restriction. For instance, when I open my fridge and find no soy milk, it's perfectly okay for me to say 'There is no soy milk'. But the corresponding existence denials'No soy milk exists' and 'Soy milk doesn't exist' — are badly infelicitous. And as Everett $(2007,67)$ points out, this seems unfortunate given that Thomasson's proposal is precisely that we understand the true claims expressed by claims like 'Hobbits don't exist' as cases of quantifier domain restriction. Or to put that point otherwise, even if the existence predicate tolerates explicit restrictions to locations or times, it doesn't seem to tolerate the range of implicit restrictions that our quantifiers tolerate.

To be fair to Everett and Walton, Thomasson does tell us that negative existential claims can be understood in terms of implicit restrictions on the domain of quantification. Thus directly after suggesting her treatment of 'There is no Lear' she writes:

Implicitly limiting the sort of entities one is quantifying over is in fact something we do all the time in our discourse, when our audience normally understands us to only be referring to relevant items. $(1999,112)$

But the cases that primarily concern her when she does so are quantificational claims like 'There are no hobbits' and 'There is no Lear'. And in these cases, Thomasson's claim is accurate. However, to say that 'There are no hobbits' involves an implicit restriction on the domain of quantification isn't to say that the sentence 'Hobbits don't exist' involves a similar restriction on the domain of quantification. Indeed, it's 
difficult to see what that claim even means, given that no quantificational expressions figure in the sentence. So in that sense Thomasson's characterization of the proposal is misleading, and at best only obviously applies to quantified negative existentials rather than explicit existence denials too.

Since she restricts her attention mainly to 'there is/there are' constructions, it's difficult to tell exactly how Thomasson is conceiving of her proposal. But it is emphatically not true on my proposal that the negated existential quantifiers of the metalanguage range over a restricted domain. For the semantic proposal serves up the following truth-condition:

'Hermione doesn't exist' is true in context c iff $\neg \exists x$ ( $x$ is a $\mathrm{K}_{\mathrm{C}} \wedge x=$ Hermione)

And notice that the domain over which the metalinguistic quantifier ranges is not restricted at all-there isn't even any mention of a domain in the truth-condition. And notice next that this is very different from the view that Walton and Everett associated with Thomasson, according to which the right-hand side of the truthcondition for 'Hermione doesn't exist' was ' $\neg \exists x(x=$ Hermione)' and then we plead domain restriction for the quantifier in the metalanguage. Indeed it is not even clear to me that this way of setting up our current proposal makes sense in the first place. When we specify the truth conditions for context-sensitive expressions, we do so in a metalanguage that is itself free from any (relevant) implicit context-sensitivity. And the only context-sensitivity involved in the proposal is associated with the relevant kind in terms of which the existence predicate is interpreted.

Nevertheless, our proposal will appeal to quantifier domain restriction when dealing with negated quantifications like 'There is no Lear' and will generate something like the following truth-condition:

'There is no Lear' is true in context $\mathrm{c}$ iff $\neg \exists x\left(x\right.$ is in $\mathrm{D}_{\mathrm{C}} \wedge x=$ Lear $)$

Here the interpretation of the target claim does appeal to a restricted domain of quantification: thus the domain over which the object-language quantifiers range is taken to be restricted to the objects in DC.

Now, in some cases, the relevant domain over which our quantifiers range may be the set of absolutely all the Ks, where $\mathrm{K}$ is the kind that is contextually relevant to the interpretation of the negative existential (the concrete objects, say). In this context, it'll turn out e.g. that both 'Hermione doesn't exist' and 'There is no Hermione' are true because nothing concrete is identical to Hermione. But such cases, while they have been the focus of this chapter, are the exception and not the norm. If I quantify over the set of things that are in my fridge, my quantifiers don't range over the set of absolutely all the concrete objects. So whilst it will be acceptable for me to say that 'There is no soy milk' (because my quantifiers are restricted to what's in my fridge) it won't be acceptable for me to say that soy milk doesn't exist.

In sum, even if Walton's objection, which Everett also endorses, is fatal against Thomasson's proposal—and I'm inclined to think that her account is underspecified to the extent that it is difficult to tell exactly how she wants to handle various 
claims - the spirit of her account can be retained. The view I have defended here does not make any important use of the phenomenon of quantifier domain restriction when interpreting existence denials. For whilst it is true that the truth-conditions are quantificational in character and appeal to a particular kind $\mathrm{K}$ that is relevant for the interpretation of the negative existential, it is not true that the quantifiers appealed to in the metalanguage are implicitly restricted to the set of Ks.

\subsection{Closing Remarks}

I have argued that, despite recent criticism, the fictional realist can account for the truth of many negative existentials about fictional characters. My proposal borrows an idea from Thomasson in that it involves the claim that negative existentials may be interpreted by reference to particular kinds. Hence, 'Hermione doesn't exist' will be true in a context iff Hermione is not a $\mathrm{K}_{C}$. The value of $\mathrm{K}$ in a given context will be typically fixed to a semantic value that may be chosen from a range of appropriate values, most prominently concrete object and serious object. Plural negative existentials are equally understood with reference to kinds. Thus, 'Superheroes don't exist' will be true in a context $\mathrm{c}$ iff there is no $x$ such that $x$ is a $\mathrm{K}_{C}$ and $x$ is a superhero.

But before I end this chapter, allow me to point out two features about the debate of negative existentials about fictional characters that I consider important.

First, there's more than one way to account for the relationship between the sentences uttered in context and the propositions the fictional realist cares about. The approach I have developed here is set up in such a way as to provide truth-conditions for negative existentials, where I think of the project of specifying truth-conditions for sentences as a semantical project. But it is important to realize that the spirit of this proposal does not require the fictional realist to conceive of herself as engaged in a semantical project. Thus rather than thinking of 'Hermione doesn't exist' as expressing a true proposition, the fictional realist may instead think of that sentence (in context) as expressing a false proposition and then attempting to accommodate our intuitions by appeal to the thought that a false sentence can nonetheless convey something true. Thus though I myself prefer the semantical understanding of the proposal, an analogous account could be developed on a more pragmatic understanding of the proposal.

Secondly, I stress that the aim of this chapter was not to argue that the account I develop here is the only plausible account of how negative existentials can be accommodated by the realist. In particular, I haven't discussed at all Thomasson's newer proposal which generalizes Donnellan's (1974) idea that a chain of reference may end in a so-called 'block' (cf. Thomasson 2007). I don't feel particularly attracted to this approach to negative existentials and it also has received its fair share of criticism by Everett. But which semantical theory is the best amongst a range of equally adequate ones is a question that needs to be settled by considering metasemantical issues, i.e. issues to do with what fixes the semantics of a language, and I suspect that one's semantic preferences will often be coordinated with a certain picture of 
how semantic theories are fixed. ${ }^{20}$ In any case, I claim only that the approach I've developed is immune to the objections that anti-realists have offered in the literature, and I thereby submit that negative existentials are not the Achilles heel of fictional realism.

\section{References}

Braun, David (2005) Empty Names, Fictional Names, Mythical Names. Noûs, 39, 596-631. Burge, Tyler (1972) Truth and Mass Terms. Journal of Philosophy, 69, 163-82.

Chappell, V. C. (1970) Stuff and Things. Proceedings of the Aristotelian Society, 71, 61-76.

Donnellan, Keith (1974) Speaking of Nothing. Philosophical Review, 83, 3-31.

Everett, Anthony (2007) Pretense, Existence and Fictional Objects. Philosophy and Phenomenological Research, 74, 56-80.

Kripke, Saul (1973) Reference and Existence. Delivered as the Locke Lectures Unpublished. Moltmann, Friederike (n.d) The Semantics of Existence. Unpublished.

Montague, Richard (1979) The Proper Treatment of Mass Terms in English. In Francis Jeffrey Pelletier (ed.), Mass Terms: Some Philosophical Problems (Dordrecht: D. Reidel), 173-8.

Quine, W. V. O. (1948) On What there is. Review of Metaphysics, 2, 21-38.

Sainsbury, Mark (2009) Fiction and Fictionalism (London: Routledge).

Salmon, Nathan (1998) Nonexistence. Noûs, 32, 277-319.

— (2002). Mythical Objects. In his Metaphysics, Mathematics, and Meaning (Oxford: OUP), 91-107.

Schaffer, Jonathan (2009) On What Grounds What. In David Chalmers, David Manley, and Ryan Wasserman (eds), Metametaphysics (Oxford: OUP), 347-83.

Schiffer, Stephen (1996) Language-Created, Language-Independent Entities. Philosophical Topics, 24, 149-67.

Thomasson, Amie L. (1999) Fiction and Metaphysics (Cambridge: CUP).

- (2003) Speaking of Fictional Characters. Dialectica, 57, 207-26.

- (2007) Ordinary Objects (New York: OUP).

van Inwagen, Peter (1977) Creatures of Fiction. American Philosophical Quarterly, 14, 299-308. - (1983) Fiction and Metaphysics. Philosophy and Literature, 7, 66-77.

_ (2003) Existence, Ontological Commitment, and Fictional Entities. In Michael J. Loux and Dean W. Zimmerman (eds), Oxford Handbook of Metaphysics (Oxford: OUP), 131-57. Walton, Kendall (2003) Restricted Quantification, Negative Existentials, and Fiction. Dialectica, 57, 239-42.

Wolterstorff, Nicholas (1980) Worlds and Works of Art (Oxford: Clarendon Press).

Yagisawa, Takashi (2001) Against Creationism in Fiction. Noûs, 35, 153-72.

Zimmerman, Dean W. (1995) Theories of Masses and Problems of Constitution. Philosophical Review, 104, 53-110.

20 Indeed, if we sharply distinguish between semantical and metasemantical issues, we might be able to combine the approach I proposed here and Thomasson's newer proposal by using the notion of blocked chains of reference to demarcate the category of pretend objects. But crucially the notion of a blocked chain of reference wouldn't be built into the semantics of negative existence. 